\title{
Badminton Field Booking Application in the Sidoarjo Region based on Android
}

\section{Aplikasi Booking Lapangan Badminton Di Wilayah Sidoarjo Berbasis Android}

\author{
Rengga Lauddipa ${ }^{1}$, Mohammad Suryawinata ${ }^{2}$ \\ \{161080200038@umsida.ac.id ${ }^{1}$, suryawinata@umsida.ac.id² $\}$
}

Universitas Muhammadiyah Sidoarjo, Indonesia ${ }^{1}$, Universitas Muhammadiyah Sidoarjo, Indonesia ${ }^{2}$

\begin{abstract}
In sidoarjo area more and more badminton court rental with quality standards that make fans play badminton more and more. in booking badminton courts still use a manual system. Then it takes innovation in technology to help in booking badminton courts. In the creation of the application using waterfall method so that the creation of the application can be completed according to the planning so as to produce the appropriate application. Implementation of the results of the study using android studio software using java programming language and using firebase database as data storage in the application in realtime. Badminton court booking application based on android can provide user convenience in booking badminton court does not have to come to the field. The application has been tested using the black box testing method on all features of the application shows a percentage of 100\% so that arguably the application runs well. Similarly, can be seen in the test using the likert scale questionnaire method for UAT results get a result of $85 \%$.
\end{abstract}

Keywords - Android; Badminton; Booking; Application

Abstrak. Di wilayah Sidoarjo semakin banyak penyewaan lapangan badminton dengan standart yang berkualitas sehingga menjadikan peminat bermain badminton semakin banyak. dalam booking lapangan badminton masih menggunkan sistem manual. Maka diperlukan inovasi dalam teknologi untuk membantu dalam booking lapangan badminton. Dalam pembuatan aplikasi menggunakan metode waterfall agar pembuatan aplikasi dapat selesai sesuai perencanaan sehingga menghasilkan aplikasi yang sesuai. Implementasi hasil penelitian menggunakan perangkat lunak android studio dengan menggunakan bahasa pemrograman java dan menggunakan database firebase sebagai penyimpanan informasi data pada aplikasi secara realtime. Aplikasi booking lapangan badminton berbasis android dapat memberikan kemudahan user dalam booking lapangan badminton tidak harus datang ke tempat lapangan tersebut. Aplikasi telah diuji menggunakan metode pengujian black box pada semua fitur aplikasi menunjukkan presentase 100\% sehingga dibilang aplikasi berjalan dengan baik. Begitu juga bisa dilihat dalam pengujian menggunakan metode angket skala likert untuk hasil UAT mendapatkan hasil 85\%.

Kata Kunci - Android; Badminton; Booking; Aplikasi

\section{Pendahuluan}

Permainan bulutangkis menjadi sebuah cabang olahraga yang sangat popular didunia. Olahraga ini diminati oleh berbagai macam kelompok umur mulai dewasa hingga anak-anak, olahraga bulutangkis dimainkan oleh putra maupun putri yang memainkan olahraga ini di lapangan indoor maupun lapangan outdoor yang terdapat persaingan antar tim. Bulutangkis atau badminton adalah suatu permaianan yang dimaikan oleh dua orang atau empat orang yang saling berlawanan yang memiliki teknik pukulan yang bervariasi yang diikuti dengan gerakan tipuan, adapun alat yang digunakan dalam permainan bulutangkis adalah net, raket, dan "kok" atau juga disebut "shuttlecock" [1].

Dengan banyaknya peminat yang menyewa lapangan badminton saat ini, olahraga bulutangkis sangat banyak digemari oleh berbagai macam kalangan muda maupun tua yang ingin bercita-cita menjadi seorang atlet ataupun hidup sehat dengan berolahraga. setelah penulis survei ke penyewaan lapangan badminton "bintang terang" di tempat penyewaan lapangan itu lumayan cukup banyak diminati oleh kalangan anak-anak hingga orang dewasa yang ingin berolahraga dan juga berlatih secara profesional, di berbagai tempat penyewaan lapangan badminton memiliki fasilitas yang berbeda-beda disetiap tempatnya.

Disini penulis menemukan banyaknya permasalahan dalam pembokingan lapangan badminton adalah masih secara manual, yaitu dengan datang ke tempat booking lapangan dan itu terasa membuang waktu dan tidak efisien. maka penulis ingin memberikan solusi dalam penyewaan lapangan badminton yang berbasis android dikarenakan di era sekarang sebagian besar orang menggunakan smartphone, supaya lebih memudahkan dalam penyewaan lapangan badminton yang tidak harus datang ketempat penyewaan lapangan badminton melainkan tinggal membuka aplikasi yang penulis buat dan tinggal membooking lapangan yang diinginkan. 
Berdasarkan penelitian sebelumnya dengan judul "Sistem informasi penyewaan lapangan pada melati futsal comal berbasis android". menjelaskan bahwa sistem reservasi yang diterapkan pada melati futsal comal adalah sistem buku tulis di tempat dan melalui telepon untuk pemesanan langsung disitu terlihat kurang peraktis, bila pemesanan melalui telepon memerlukan validasi yang akurat dan hanya bisa dilakukan oleh orang yang sudah menjadi member atau sudah dikenal dan itu memiliki resiko tinggi [2].

Berdasarkan penelitian sebelumnya penulis merasa kurang maksimal di karenakan masih menggunakan telepon atau manual dalam hal penyewaan lapangan futsal dan juga penyimpanan data penyewa masih menggunakan buku yang ditulis dengan tangan.

Oleh sebab itu, dibutuhkan sebuah sistem aplikasi berbasis android untuk booking lapangan badminton secara online agar penyewa tidak kesulitan dalam penyewaan lapangan badminton dan tidak harus datang ke tempat penyewaan lapangan badminton sehingga tidak memakan waktu bagi penyewa dan bisa lebih efisien.

\section{METODE}

\section{A. Teknik Pengumpulan Data}

Teknik pengumpulan data adalah alat bantu yang digunakan oleh peneliti dalam mengumpulkan data agar menjadi sistematis dan dapat mempermudah dalam pengumpulan data[3]. Berikut ini teknik pengumpulan data sebagai berikut: (a) Observasi dengan cara mengunjungi dan mengamati secara langsung lokasi penyewaan lapangan badminton yang digunakan untuk menganalisa data dan informasi bagaimana cara boking lapangan badminton, untuk tercapainya tujuan pembuatan aplikasi ini. (b) Wawancara merupakan teknik pengumpulan data yang disini penulis melakukan tanya jawab langsung dengan cara bertatap muka, dengan ini bertujuan untuk mengetahui apa saja permasalahan yang ada di penyewaan lapangan badminton tersebut. (c) Studi literatur suatu teknik pengumpulan data lebih lanjut melalui mengumpulkan informasi dari sumber terpercaya seperti jurnal, website resmi, buku atau para ahli yang berhubungan dengan pembahasan pada aplikasi ini. Karena dalam pembuatan aplikasi ini diperlukan survey dilapangan untuk menganalisa suatu permasalahan yang telah terjadi pada sistem boking lapangan badminton. dan juga melakukan wawancara ke pihak pengelola yang bersangkutan untuk mewujudkan perkembangan dari sistem aplikasi ini.

\section{B. Perancangan Aplikasi}

Dalam perancangan aplikasi menggunakan metode waterfall adalah suatu model berbentuk air terjun yang sering disebut juga model sekuensial linier (sequential linear). Model waterfall menggunakan pendekatan perangkat lunak secara sekuensial atau terurut dimulai dari analisis, desain, penulisan kode program, pengujian, dan pemeliharaan aplikasi[4].

Metode yang digunakan dalam aplikasi yaitu menggunakan metode Waterfall yang memiliki tahapan sebagai berikut : (a) Analisis kebutuhan aplikasi dalam mengumpulkan data pada sebuah penelitian untuk mengindentifikasi masalah, pada analisa data yang telah dikumpulkan guna membangun aplikasi sesuai keinginan yang dibuat. (b) Desain sistem dalam perencanaan aplikasi yang harus dilakukan yaitu membuat Use Case Diagram, Entity Relationship Diagram, Activity Diagram, Sequence Diagram dan Interface desain. (c) Penulisan kode program aplikasi yang dikerjakan secara nyata dan maksimal seperti yang harus dilakukan yaitu membuat script code program untuk merancang aplikasi Booking Lapangan Badminton berbasis Android yang telah direncanakan. (d) Pengujian Program aplikasi ini bisa dikatakan tahapan terakhir dalam sebuah pembuatan aplikasi yaitu harus dilakukan pengujian aplikasi untuk mengetahui kekurangan dan mengevaluasi aplikasi tersebut untuk dilakukan perbaikan. (e) Pemeliharaan aplikasi pasti mengalami perubahan dikarenakan harus menyesuaikan dengan sistem operasi baru karena aplikasi membutuhkan perkembangan secara fungsi. pada tahap ini juga diterapkan pada aplikasi booking lapangan badminton yang selanjutnya akan dilakukan pemeliharaan secara berkala dan evaluasi aplikasi tersebut.

\section{Activity Diagram}

Activity diagram adalah suatu gambaran alur logika sistem yang menunjukkan langkah-langkah dalam aliran kerja sistem atau aktivitas sebuah sistem yang masing-masing memiliki tanggung jawab menyelesaikan suatu obyek-obyek dalam aliran kerja sistem sehingga memudahkan dalam merancang sebuah sistem yang sesuai keinginan[5]. Pada activity diagram dibawah ini menjelaskan alur kerja sistem yang bisa dilihat pada gambar dibawah ini: 


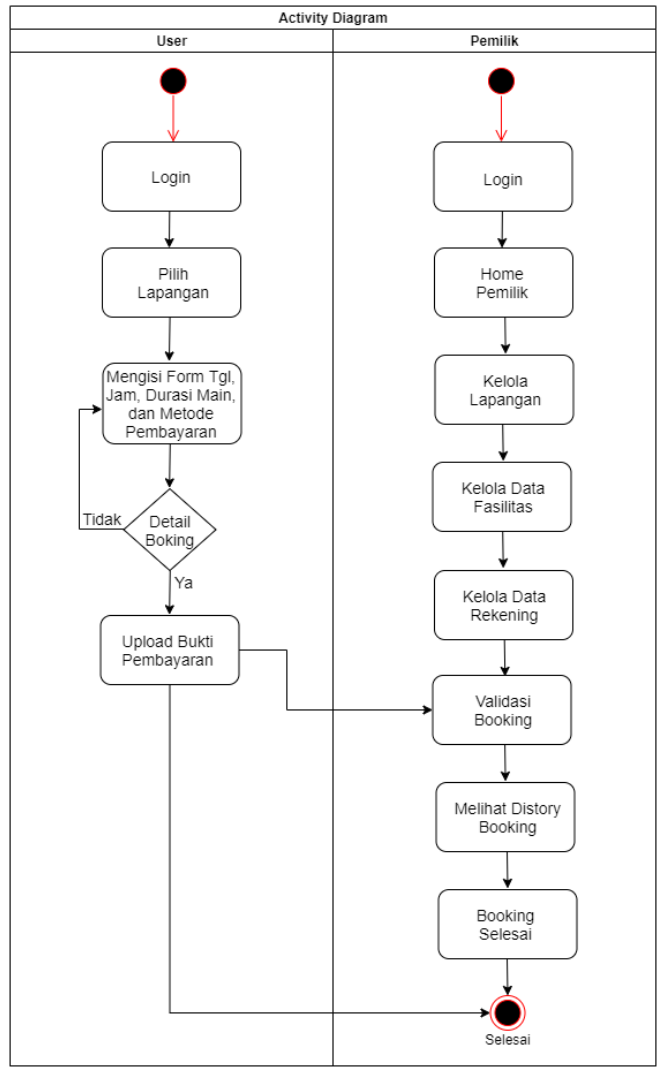

Gambar 1. Activity Diagram

\section{Hasil dan Pembahasan}

\section{A. Hasil Tampilan Aplikasi}

Aplikasi adalah perangkat lunak yang menjadi bagian terakhir yang dirancang untuk pengolahan data yang bisa diaplikasikan menjadi sebuah sistem informasi yang bisa melakukan tugas yang diinginkan pengguna dan juga aplikasi yang bersangkutan[6]. Pada hasil tampilan aplikasi ini memiliki tiga tampilan yaitu tampilan user, tampilan pemilik lapangan badminton, dan tampilan admin. berikut ini adalah tampilan registrasi dan login dimana para pemakai aplikasi diwajibkan memiliki akun untuk dapat memakai aplikasi yang dapat dilihat pada gambar 1 dibawah ini.
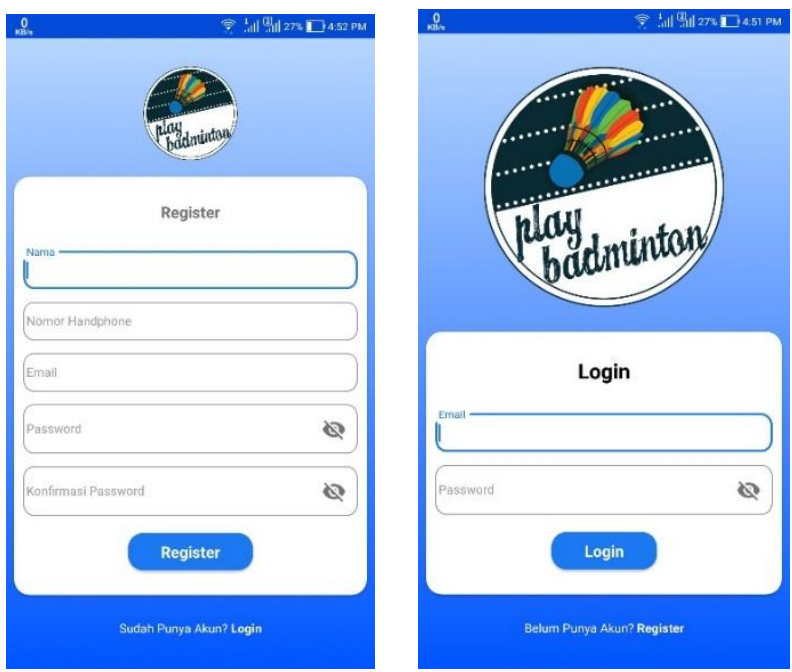

Gambar 1. Tampilan Halaman Registrasi dan Login

Selanjutnya halaman tampilan home user aplikasi ini menampilkan tampilan partner lapangan yang sudah terdaftar pada aplikasi, user dapat memilih lapangan yang ingin dibooking dan juga user dapat melihat status booking, history booking, dan akun yang dapat dilihat pada gambar 2 dibawah ini. 


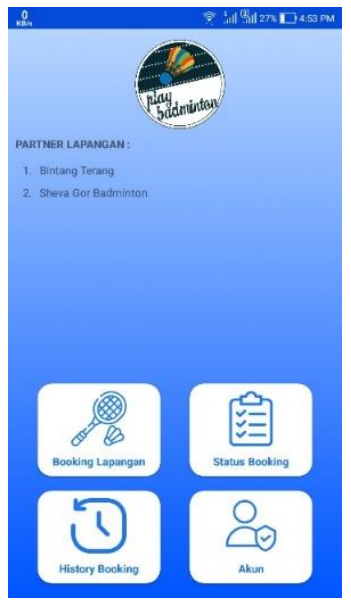

Gambar 2. Tampilan Halaman Home User

Selanjutnya tampilan halaman booking lapangan disini user dapat memilih lapangan yang diinginkan terdapat informasi nama tempat, pilihan lapangan, dan harga sesuai kebutuhan user yang dapat dilihat pada gambar 3 dibawah ini.

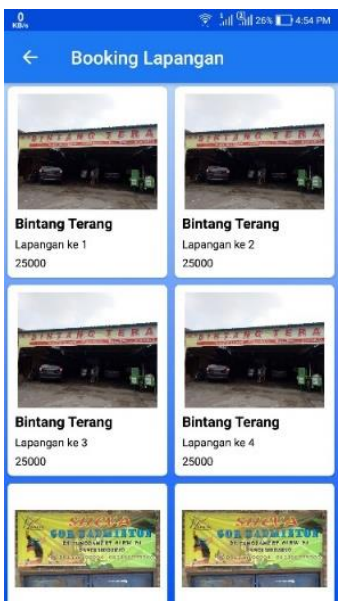

Gambar 3. Tampilan Halaman Booking Lapangan

Selanjutnya tampilan halaman form booking disini user diharuskan memilih tanggal main, jam main,durasi main, dan juga memilih pembayaran yang dapat dilihat pada gambar 4 dibawah ini.

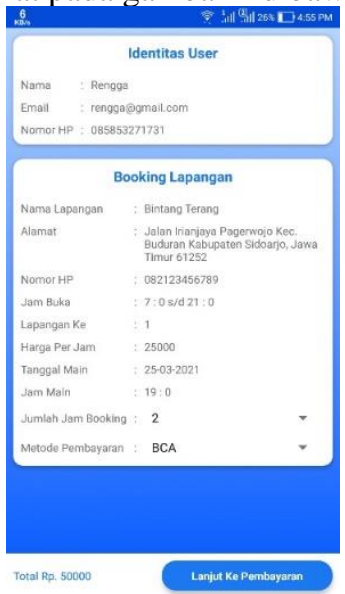

Gambar 4. Tampilan Halaman Form Booking

Selanjutnya tampilan halaman pembayaran pada tampilan pembayaran pembooking diwajibkan membayar dan upload bukti pembayaran yang sudah tersedia yang dapat dilihat pada gambar 5 dibawah ini. 


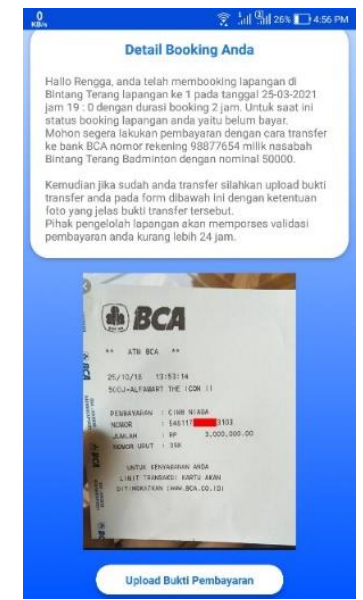

Gambar 5. Tampilan Halaman Pembayaran

Selanjutnya tampilan halaman status booking pada halaman status booking ini menjelaskan jika telah berhasil melakukan booking lapangan badminton yang dapat dilihat pada gambar 6 dibwah ini.

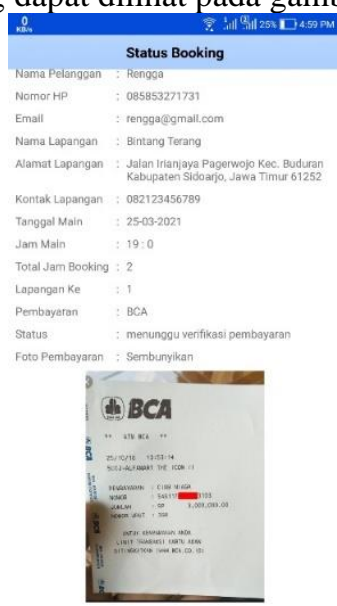

Gambar 6. Tampilan Halaman Status Booking

Selanjutnya tampilan halaman home pemilik ini pemilik bisa mengelola lapangan, fasilitas, rekening, validasi, history, dan informasi akun, begitu juga dapat melihat list booking hari ini yang dapat dilihat pada gambar 7 dibawah ini.

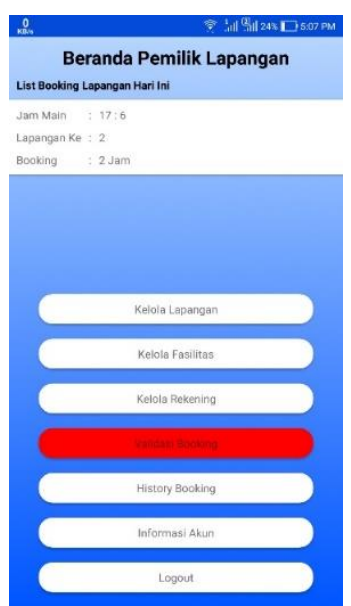

Gamabar 7. Tampilan Halaman Home Pemilik

Selanjutnya tampilan halaman validasi booking pemilik berhak memvalidasi atau menolak jika bukti pembayaran tidak sesuai yang dapat dilihat pada gambar 8 dibawah ini. 


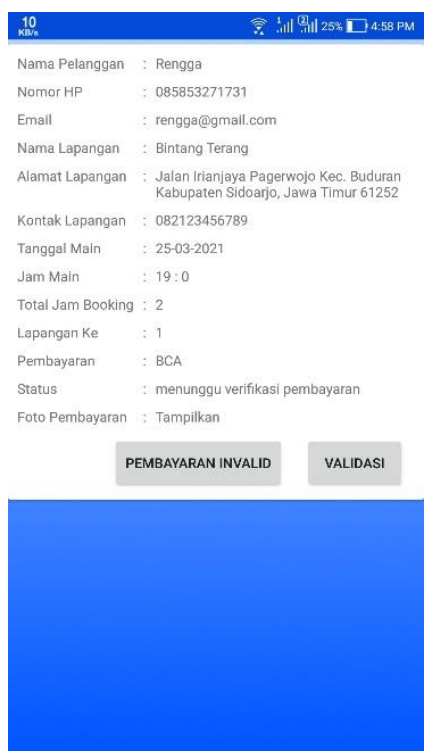

Gambar 8. Tampilan Halaman Validasi Booking

Selanjutnya tampilan halaman home admin ini admin dapat mengelola lapangan, user, history booking, dan rekening yang dapat dilihat pada gambar 9 dibawah ini.

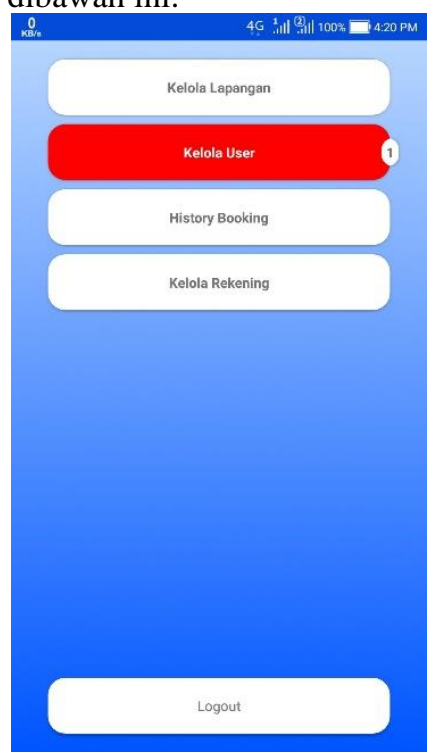

Gambar 9. Tampilan Halaman Home Admin

\section{B. Hasil Pengujian Sistem}

Pengujian sistem adalah suatu proses sistem perangkat lunak untuk menentukan sistem perangkat lunak tersebut cocok dengan spesifikasi sistem sehingga dapat berjalan sesuai yang diinginkan [7].

Pada setiap pembuatan aplikasi dibutuhkan pengujian sistem untuk menguji semua fitur yang ada di aplikasi dan juga untuk memastikan setiap fungsi dari aplikasi tersebut berjalan dengan baik dan benar. Didalam pengujian menggunakan metode black box merupakan pengujian yang berfokus kepada spesifikasi fungsionalitas dari sistem perangkat lunak. yang didasarkan detail aplikasi seperti fungsi-fungsi dasar aplikasi[8]. disini menjelaskan tiga tebel pengujian sistem yaitu pengujian sistem user, pengujian sistem pemilik, dan pengujian sistem admin. berikut tabel rencana pengujian fungsi dasar sistem sebagai berikut:

Tabel 1. Pengujian Sistem User

\begin{tabular}{|c|l|l|l|c|}
\hline No & \multicolumn{1}{|c|}{ Fitur } & \multicolumn{1}{|c|}{ Hasil Yang Diharapan } & \multicolumn{1}{c|}{ Pengamatan } & Hasil \\
\hline 1 & Fitur login user & $\begin{array}{l}\text { Apabila login sesuai data login } \\
\text { user yang sudah terdaftar, maka } \\
\text { sistem akan masuk ke dalam home } \\
\text { user }\end{array}$ & $\begin{array}{l}\text { Data login user benar maka } \\
\text { menampilkan home user }\end{array}$ & Berhasil \\
\hline
\end{tabular}


Procedia of Engineering and Life Science Vol. 1. No. 1 March 2021

Seminar Nasional \& Call Paper Fakultas Sains dan Teknologi (SENASAINS 1st)

Universitas Muhammadiyah Sidoarjo

\begin{tabular}{|c|c|c|c|c|}
\hline 2 & Fitur registrasi user & $\begin{array}{l}\text { Apabila registrasi yang sudah } \\
\text { diinputkan secara benar dan } \\
\text { lengkap maka sistem akan } \\
\text { memproses data untuk selanjutnya } \\
\text { disimpan ke dalam database }\end{array}$ & $\begin{array}{l}\text { Sistem dapat memproses data dan } \\
\text { menyimpan akun user }\end{array}$ & Berhasil \\
\hline 3 & $\begin{array}{l}\text { Fitur booking } \\
\text { lapangan }\end{array}$ & $\begin{array}{l}\text { User dapat melihat pilihan } \\
\text { lapangan dan melakukan booking } \\
\text { lapangan dan masuk ke dalam } \\
\text { status booking }\end{array}$ & $\begin{array}{l}\text { Sistem dapat melakukan proses } \\
\text { booking sesuai keinginan user }\end{array}$ & Berhasil \\
\hline 4 & Fitur pembayaran & $\begin{array}{l}\text { Pilihan rekening akan muncul saat } \\
\text { booking lapangan }\end{array}$ & $\begin{array}{l}\text { Sistem dapat menampilkan } \\
\text { pilihan rekening dan dapat dipilih } \\
\text { sesuai keinginan user }\end{array}$ & Berhasil \\
\hline 5 & $\begin{array}{l}\text { Fitur upload bukti } \\
\text { pembayaran }\end{array}$ & $\begin{array}{l}\text { User dapat melakukan upload } \\
\text { bukti pembayaran dan akan } \\
\text { tersimpan pada status booking }\end{array}$ & $\begin{array}{l}\text { Sistem dapat menyimpan bukti } \\
\text { pembayaran dan akan muncul } \\
\text { pada status booking }\end{array}$ & Berhasil \\
\hline 6 & Fitur status booking & $\begin{array}{l}\text { Dapat menampilkan detail } \\
\text { booking dan status pembayaran } \\
\text { yang sudah dilakukan user }\end{array}$ & $\begin{array}{l}\text { Sistem dapat menampilkan detail } \\
\text { booking dan status pembayaran }\end{array}$ & Berhasil \\
\hline
\end{tabular}

Berdasarkan hasil dari uji coba fungsi fitur pada aplikasi ditabel diatas menggunakan metode black box dapat dilihat hasil data fungsional sebagai berikut:

\begin{tabular}{|c|c|l|}
\hline Tercapai $=$ & $\frac{6}{6}$ & $\times 100 \%=100 \%$ \\
\hline Gagal $=$ & $\frac{0}{6}$ & $\times 100 \%=0 \%$ \\
\hline
\end{tabular}

Tabel 2. Pengujian Sistem Pemilik

\begin{tabular}{|c|c|c|c|c|}
\hline No & Fitur & Hasil Yang Diharapan & Pengamatan & Hasil \\
\hline 1 & Fitur login pemilik & $\begin{array}{l}\text { Apabila login sesuai data login } \\
\text { pemilik yang sudah terdaftar, } \\
\text { maka sistem akan masuk ke dalam } \\
\text { home pemilik }\end{array}$ & $\begin{array}{l}\text { Data login pemik benar maka } \\
\text { menampilkan home pemilik }\end{array}$ & Berhasil \\
\hline 2 & $\begin{array}{ll}\text { Fitur } & \text { registrasi } \\
\text { pemilik } & \end{array}$ & $\begin{array}{l}\text { Apabila registrasi yang sudah } \\
\text { diinputkan secara benar dan } \\
\text { lengkap maka sistem akan } \\
\text { memproses data untuk selanjutnya } \\
\text { disimpan ke dalam database }\end{array}$ & $\begin{array}{l}\text { Sistem memproses data dan } \\
\text { menyimpan akun pemilik }\end{array}$ & Berhasil \\
\hline 3 & $\begin{array}{l}\text { Fitur pengajuan } \\
\text { pemilik }\end{array}$ & $\begin{array}{l}\text { Apabila data yang diinputkan } \\
\text { secara benar dan lengkap maka } \\
\text { akan diproses untuk di verifikasi } \\
\text { oleh admin }\end{array}$ & $\begin{array}{l}\text { Sistem memproses data yang } \\
\text { sudah diverifikasi oleh admin dan } \\
\text { tersimpan pada database }\end{array}$ & Berhasil \\
\hline 4 & Fitur kelola lapangan & $\begin{array}{l}\text { Dapat mengelola lapangan dan } \\
\text { menambahkan lapangan }\end{array}$ & $\begin{array}{l}\text { Sistem memproses data lapangan } \\
\text { yang sudah ditambahkan }\end{array}$ & Berhasil \\
\hline 5 & Fitur kelola fasilitas & $\begin{array}{l}\text { Dapat mengelola fasilitas } \\
\text { lapangan dan menambahkan } \\
\text { fasilitas lapangan }\end{array}$ & $\begin{array}{l}\text { Sistem memproses data fasilitas } \\
\text { yang sudah ditambahkan }\end{array}$ & Berhasil \\
\hline 6 & Fitur kelola rekening & $\begin{array}{l}\text { Dapat mengelola rekening dan } \\
\text { menambahkan rekening }\end{array}$ & $\begin{array}{l}\text { Sistem memproses data rekening } \\
\text { yang sudah ditambahkan }\end{array}$ & Berhasil \\
\hline 7 & Fitur validasi booking & $\begin{array}{l}\text { Dapat memvalidasi maupun } \\
\text { invalidasi pembayaran user }\end{array}$ & $\begin{array}{l}\text { Sistem memproses validasi } \\
\text { pembayaran user }\end{array}$ & Berhasil \\
\hline 8 & Fitur history booking & $\begin{array}{l}\text { Dapat menampilkan seluruh detail } \\
\text { booking }\end{array}$ & $\begin{array}{l}\text { Sistem memproses semua detail } \\
\text { booking }\end{array}$ & Berhasil \\
\hline 9 & Fitur informasi akun & $\begin{array}{l}\text { Menampilkan informasi akun dan } \\
\text { informasi lapangan, pemilik dapat } \\
\text { mengubah dengan benar }\end{array}$ & $\begin{array}{l}\text { Sistem dapat diakses oleh pemilik } \\
\text { dan dapat memproses informasi } \\
\text { akun yang sudah di rubah dengan } \\
\text { benar }\end{array}$ & Berhasil \\
\hline
\end{tabular}

Berdasarkan hasil dari uji coba fungsi fitur pada aplikasi ditabel diatas menggunakan metode black box dapat dilihat hasil data fungsional sebagai berikut: 
Procedia of Engineering and Life Science Vol. 1. No. 1 March 2021

Seminar Nasional \& Call Paper Fakultas Sains dan Teknologi (SENASAINS 1st)

Universitas Muhammadiyah Sidoarjo

(2)

\begin{tabular}{|c|c|l|}
\hline Tercapai $=$ & $\frac{9}{9}$ & x $100 \%=100 \%$ \\
\hline Gagal $=$ & $\frac{0}{9}$ & $\times 100 \%=0 \%$ \\
\hline
\end{tabular}

Tabel 3. Pengujian Sistem Admin

\begin{tabular}{|c|c|c|c|c|}
\hline No & Fitur & Hasil Yang Diharapan & Pengamatan & Hasil \\
\hline 1 & Fitur login admin & $\begin{array}{l}\text { Apabila login sesuai data login } \\
\text { admin yang sudah terdaftar, maka } \\
\text { sistem akan masuk ke dalam home } \\
\text { admin }\end{array}$ & $\begin{array}{l}\text { Data login admin benar maka } \\
\text { menampilkan home admin }\end{array}$ & Berhasil \\
\hline 2 & Fitur kelola lapangan & $\begin{array}{l}\text { Menampilkan data lapangan dan } \\
\text { dapat dihapus jika tidak sesuai }\end{array}$ & $\begin{array}{l}\text { Sistem memproses data lapangan } \\
\text { dan dapat dihapus jika tidak } \\
\text { sesuai }\end{array}$ & Berhasil \\
\hline 3 & $\begin{array}{l}\text { Fitur kelola user dan } \\
\text { pemilik }\end{array}$ & $\begin{array}{l}\text { Menampilkan list user dan list } \\
\text { pemilik dan juga admin dapat } \\
\text { memverifikasi pengajuan pemilik } \\
\text { lapangan }\end{array}$ & $\begin{array}{l}\text { Sistem memproses list user dan } \\
\text { list pemilik dan juga } \\
\text { menampilkan } \\
\text { pengajuan pemilik lapangan }\end{array}$ & Berhasil \\
\hline 4 & Fitur kelola rekening & $\begin{array}{l}\text { Menampilkan daftar seluruh } \\
\text { rekening yang digunakan pemilik } \\
\text { dan dapat menghapus jika tidak } \\
\text { benar }\end{array}$ & $\begin{array}{l}\text { Sistem memproses daftar data } \\
\text { rekening pemilik dan dapat } \\
\text { menghapus jika tidak benar }\end{array}$ & Berhasil \\
\hline
\end{tabular}

Berdasarkan hasil dari uji coba fungsi fitur pada aplikasi ditabel diatas menggunakan metode black box dapat dilihat hasil data fungsional sebagai berikut:

\begin{tabular}{|c|l|l|}
\hline Tercapai $=$ & $\frac{4}{4}$ & x $100 \%=100 \%$ \\
\hline Gagal $=$ & $\frac{0}{4}$ & $\times 100 \%=0 \%$ \\
\hline
\end{tabular}

Hasil dari pengujian dinyatakan sangat baik karena semua sistem berfungsi dengan baik dan benar sesuai perancangan yang dibuat.

\section{Hasil Pengujian UAT}

User Acceptance Testing adalah suatu pengujian yang dimana end-user dimana user adalah seorang yang berinteraksi dengan sistem dan melakukan verifikasi apakah fungsi sistem telah sesuai dengan kebutuhan[9].

Tahap penelitian menggunakan User Acceptance Testing untuk tahapan akhir pengujian yang bertujuan untuk mengetahui hasil dari aplikasi apakah masih terdapat ketidak sesuaian pada perancangan aplikasi. pada tahap pengujian angket skala likert berguna untuk mengukur pendapat seseorang untuk melihat hasil setiap jawaban[10] yang biasanya digunakan dalam riset yang berupa survei serta membagikan pertanyaan kepada pengguna aplikasi dimana jawaban dari pertanyaan terdiri dari beberapa macam nilai yang dapat dipilih pada tabel dibawah ini.

Tabel 4. Tabel Bobot Nilai Jawaban

\begin{tabular}{|c|c|}
\hline Keterangan & Bobot \\
\hline Sangat Setuju & 5 \\
\hline Setuju & 4 \\
\hline Cukup & 3 \\
\hline Kurang Setuju & 2 \\
\hline Sangat Tidak Setuju & 1 \\
\hline
\end{tabular}

Pada tabel dibawah ini menjelaskan pertanyaan yang akan digunakan penulis guna mendapatkan hasil data pendukung untuk hasil penelitian ini dalam pengisian pertanyaan menggunakan google form yang dapat dilihat pada link berikut ini https://forms.gle/apuiJwgyc3Tq3Yp38 sebagai berikut:

Tabel 5. Tabel Daftar Pertanyaan 
Procedia of Engineering and Life Science Vol. 1. No. 1 March 2021

Seminar Nasional \& Call Paper Fakultas Sains dan Teknologi (SENASAINS 1st)

Universitas Muhammadiyah Sidoarjo

\begin{tabular}{|c|l|}
\hline No & \multicolumn{1}{|c|}{ Pertanyaan } \\
\hline 1 & Apakah tampilan antarmuka aplikasi booking lapangan badminton di wilayah Sidoarjo menarik? \\
\hline 2 & $\begin{array}{l}\text { Apakah tampilan registrasi dan login dapat dijalankan dengan mudah dan sesuai dengan data akun } \\
\text { anda yang sudah teregistrasi sebelumnya? }\end{array}$ \\
\hline 3 & $\begin{array}{l}\text { Apakah dalam proses booking lapangan di aplikasi booking lapangan badminton di wilayah } \\
\text { Sidoarjo dapat dioperasikan dengan mudah? }\end{array}$ \\
\hline 4 & Apakah fitur status booking memudahkan dalam memantau booking lapangan badminton? \\
\hline 5 & $\begin{array}{l}\text { Apakah aplikasi booking lapangan badminton di wilayah Sidoarjo dapat mempermudah dalam } \\
\text { booking lapangan badminton? }\end{array}$ \\
\hline 6 & Apakah aplikasi booking lapangan badminton di wilayah Sidoarjo sesuai dengan kebutuhan? \\
\hline
\end{tabular}

Pada tabel dibawah ini menjelaskan hasil dari kuesioner yang diberikan kepada responden yang kemudian dianalisis dengan menerapkan perhitungan rata-rata skor hasil dari jawaban responden sebagai berikut:

Tabel 6. Tabel Hasil Kuesioner

\begin{tabular}{|c|c|c|c|c|c|}
\hline \multirow{2}{*}{$\begin{array}{c}\text { No } \\
\text { Pertanyaan }\end{array}$} & \multicolumn{6}{|c|}{ Frekuensi Jawaban } \\
\hline & $\mathbf{5}$ & $\mathbf{4}$ & $\mathbf{3}$ & $\mathbf{2}$ & $\mathbf{1}$ \\
\hline P1 & 4 & 5 & 1 & 0 & 0 \\
\hline P2 & 3 & 6 & 1 & 0 & 0 \\
\hline P3 & 2 & 6 & 2 & 0 & 0 \\
\hline P4 & 5 & 4 & 1 & 0 & 0 \\
\hline P5 & 3 & 7 & 0 & 0 & 0 \\
\hline P6 & 4 & 5 & 1 & 0 & 0 \\
\hline Total Skor & 21 & 33 & 6 & 0 & 0 \\
\hline
\end{tabular}

Tabel 7. Tabel Bobot Jumlah Skor

\begin{tabular}{|c|c|c|}
\hline Jumlah Skor & Perkalian & Hasil \\
\hline Jumlah Bobot 5 & $21 \times 5$ & 105 \\
\hline Jumlah Bobot 4 & $33 \times 4$ & 132 \\
\hline Jumlah Bobot 3 & $6 \times 3$ & 18 \\
\hline Jumlah Bobot 2 & $0 \times 2$ & 0 \\
\hline Jumlah Bobot 1 & $0 \times 1$ & 0 \\
\hline \multicolumn{2}{|c|}{ Jumlah Skor } & 255 \\
\hline
\end{tabular}

Berikut ini adalah hasil dari jawaban yang diberikan oleh 10 responden sehingga mendapatkan nilai tertingi sampai dengan nilai terendah yang dijelaskan sebagai berikut:

1. Nilai tertinggi $10 \times 6 \times 5=300$ (Seandainya semua menjawab 5)

2. Nilai terendah $10 \times 6 \times 1=60$ (Seandainya semua menjawab 1$)$

Jadi hasil perhitungan diatas menyatakan bahwa nilai tertinggi mendapatkan hasil 300 sehingga dapat dicari presentase pada rumus dibawah ini sebagai berikut:

$$
\frac{\mathrm{x}}{\mathrm{Y}} \times 100 \%
$$

Keterangan x merupakan jumlah skor dan y merupakan nilai tertinggi sehingga dapat diketahui tanggapan dari para responden terhadap aplikasi booking lapangan badminton di wilayah Sidoarjo berdasarkan tingkat penerimanya dinyatakan kuat yaitu dengan presentase $85 \%$

\section{KESIMPULAN}

Dari penjelasan diatas bisa disimpulkan bahwa adanya aplikasi booking lapangan badminton di wilayah sidoarjo ini diharapkan bisa membantu penyewa dalam menyewa lapangan badminton sehingga mempermudah dalam booking lapangan yang tidak harus datang ke tempat penyewaan lapangan badminton sehingga tidak memakan waktu bagi penyewa dan bisa lebih efisien. Sehingga memberikan inovasi dalam booking lapangan badminton agar tidak ketinggalan zaman yang serba digital. Sesuai nilai yang didapatkan dari pengujian diatas semua fitur aplikasi menunjukkan presentase $100 \%$ sehingga dibilang aplikasi sangat layak digunakan. Bisa juga dilihat dalam pengujian menggunakan metode angket skala likert untuk hasil user mendapatkan hasil 85\% dengan jumlah 10 responden. 


\section{REFERENSI}

[1] B. R. Juang, “Analisis Kelebihan dan Kelemahan Keterampilan Teknik Bermain Bulutangkis Pada Pemain Tunggal Putra Terbaik Indonesia Tahun 2014,” J. Kesehat. Olahraga, vol. 3, no. 1, pp. 109-117, 2015.

[2] A. Fatkhudin and D. Wicaksana, "Sistem informasi penyewaan lapangan pada melati futsal comal berbasis android," vol. 6, no. 1, 2019.

[3] Arikunto S, Penelitian suatu pendekatan praktek. Jakarta: Gramedia, 2008.

[4] J. Cordeaux, "Wicks' of the mouth," Notes Queries, vol. s5-VII, no. 159, p. 37, 1877.

[5] Sholiq, Pemodelan Sistem Informasi Berorientasi Objek Dengan UML. Yogyakarta: Graha Ilmu, 2006.

[6] A. T. J. Kiki Rizki, Shinta Esabella, "Rancang Bangun Aplikasi Jango ( Kunjungan ) Desa Berbasis Web ( Studi Kasus Desa Mama Kabupaten Sumbawa )," J. Jinteks, vol. 1, no. 1, pp. 50-57, 2019.

[7] Hanif Al Fatta, Analisis dan perancangan sistem informasi. Yogyakarta: Andi, 2007.

[8] M. S. Mustaqbal, R. F. Firdaus, and H. Rahmadi, "PENGUJIAN APLIKASI MENGGUNAKAN BLACK BOX TESTING BOUNDARY VALUE ANALYSIS (Studi Kasus : Aplikasi Prediksi Kelulusan SNMPTN)," vol. I, no. 3, pp. 31-36, 2015.

[9] W. E. Perry, Effective Methods for Software Testing: Includes Complete Guidelines, Checklists, and Templates. 2007.

[10] Sugiyono, Metode penelitian pendidikan pendekatan kuantitatif, kualitatif, dan R\&D. Bandung: Alfabeta, 2010. 